\title{
MANAJEMEN RISIKO KESELAMATAN DAN KESEHATAN KERJA (K3) PADA PROYEK PEMBANGUNAN JAMBULUWUK HOTEL \& RESORT PETITENGET
}

\author{
Anak Agung Bayu Dharma ${ }^{1}$, I Gusti Agung Adnyana Putera ${ }^{2}$, dan Anak Agung Diah Parami ${ }^{2}$
}

\begin{abstract}
Abstrak: Kecelakaan kerja yang terjadi pada proyek konstruksi akan menjadi salah satu penyebab terganggunya atau terhentinya aktivitas pekerjaan proyek. Sektor konstruksi merupakan penyumbang tertinggi kasus kecelakaan dan sakit akibat kerja di Bali, maraknya pembangunan sarana penginapan sementara atau hotel di Bali dapat menjadi salah satu penyebab terjadinya kecelakaan kerja. Penelitian ini bertujuan untuk mengetahui potensi-potensi bahaya dan risiko dominan apa saja yang terdapat pada proses pembangunan hotel serta memberikan tindakan pencegahan dalam mereduksi risiko tersebut. Pada penelitian ini metode yang digunakan adalah deskriptif kualitatif. Risiko Keselamatan dan Kesehatan Kerja (K3) diidentifikasi melalui JSA (Job Safety Analysis). Penyebaran kuisioner dilakukan untuk mendapat tanggapan mengenai paparan potensi bahaya yang teridentifikasi dari para expert di lapangan. Penilaian risiko yang berkategori dominan diperingkat melalui konsep ALARP (As Low As Reasonably Practicable). Dari hasil penelitian teridentifikasi sebanyak 45 risiko dominan yang terdapat pada tahapan pekerjaan struktur antara lain 43 risiko yang tergolong risiko tinggi (high risk) seperti : terkena manuver alat berat dan kendaraan, alat berat terguling karena area galian longsor / amblas, tali seling Tower Crane terputus/ terjerat pada pengoperasian, muatan jatuh dari Tower Crane dan sebanyak 2 risiko tergolong risiko sangat tinggi (extreme risk) yaitu : terkena manuver alat mixer dan swing Tower Crane melewati batas area proyek. Dalam meminimalkan dampak risiko K3 perlu dilakukan pengendalian risiko, evaluasi secara periodik harian, mingguan, dan evaluasi bulanan, pertimbangan jarak aman sumber bahaya dari pekerja, pengaturan jam kerja, penetapan prosedur skenario keadaan darurat dan instruksi kerja.
\end{abstract}

Kata Kunci : manajemen risiko, keselamatan dan kesehatan kerja, JSA, K3 konstruksi

\section{RISK MANAGEMENT OF OCCUPATIONAL HEALTH AND SAFETY (K3) IN THE DEVELOPMENT PROJECTS OF JAMBULUWUK HOTEL \& RESORT PETITENGET}

\begin{abstract}
Work accidents that occur on the construction project will be one of the causes of the disruption or cessation of activities of the project work. The construction sector is the highest contributor to work accidents and occupational illness in Bali. Rampant construction of temporary lodging facilities or hotels in Bali can be one of the contributors to accidents. This study aims to determine the potential hazard and any dominant risk contained in a hotel development process as well as provides preventive measures to reduce such risks. In this research, the method used was descriptive qualitative. The risk of Occupational Health and Safety (K3) was identified through JSA (Job Safety Analysis). Questionnaire survey was carried out to get feedback from the experts regarding the potential hazards identified. The dominant category of risk assessment that was rated by the concept of ALARP (As Low As Reasonably Practicable). The research identified 45 of dominant risks contained in the phase of work structures including 43 risks classified as high risk such as : exposed to maneuver heavy equipment and vehicles, heavy equipment rolled because the excavated area slid down/ subsided, cross rope of Tower Crane disconnected / entangled on the operation, the charge fell from Tower Crane and as many as two risks were classified as very high risk (extreme risk) that is : exposed to maneuver mixer and swing Tower Crane over the edge area of the project. The risks tended to be sourced in the work environment factors and work equipment. In order to minimize the impact of $\mathrm{K} 3$ risks, it is necessary to conduct risk control, evaluation activities in a daily, weekly, monthly periodic, considering a safe distance hazard source from workers, setting working hours, scenario procedures of an emergency, as well as safe work through work instruction to remind the importance of working in a healthy and safe condition.
\end{abstract}

Keywords : risk management, occupational health and safety, JSA, K3 construction

\footnotetext{
${ }^{1}$ Mahasiswa Program Magister Teknik Sipil, Fakultas Teknik, Universitas Udayana, Denpasar

${ }^{2}$ Staf Pengajar Program Magister Teknik Sipil, Fakultas Teknik, Universitas Udayana, Denpasar
} 


\section{PENDAHULUAN}

Kecelakaan kerja yang terjadi pada proyek konstruksi akan menjadi salah satu penyebab terganggunya atau terhentinya aktivitas pekerjaan proyek. Risiko kegagalan (risk of failures) selalu ada pada setiap aktifitas pekerjaan dan saat kecelakaan kerja (work accident) terjadi, seberapapun kecilnya, dapat mengakibatkan efek kerugian (loss). Karena itu sebisa mungkin dan sedini mungkin, potensi kecelakaan kerja harus dicegah atau setidaktidaknya dikurangi dampaknya. Secara historis peraturan tentang Keselamatan dan Kesehatan Kerja (K3) di Indonesia telah ada sejak pemerintahan Hindia Belanda. Setelah jaman kemerdekaan dan diberlakukannya Undang-undang Dasar 1945, maka beberapa peraturan termasuk peraturan keselamatan kerja yang pada saat itu berlaku yaitu Veiligheids Reglement telah dicabut dan diganti dengan Undang-undang Keselamatan Kerja No.1 Tahun 1970. Berdasarkan data Kementrian Kesehatan jumlah kasus kecelakaan kerja tertinggi tahun 2014 adalah Sulsel, Riau, dan Bali, sedangkan jumlah pekerja yang sakit akibat kerja tertinggi tahun 2014 adalah Bali. Sektor konstruksi merupakan penyumbang kecelakaan tertinggi, yakni $31,9 \%$ dari total kecelakaan yang terjadi. Pembangunan gedung-gedung berlantai seperti sarana penginapan sementara/ hotel akan terus berkembang seiring jaman dan teknologi karena jasa penginapan sementara/ hotel tersebut merupakan kontribusi besar bagi sektor pariwisata. Pada saat pelaksanaan pekerjaan konstruksi pembangunan sarana-sarana seperti hotel ini pada khususnya yang secara otomatis dapat mengundang terjadinya kecelakaan kerja pada proses pembangunan hotel tersebut. PT. Archouse selaku pemilik dan pengembang Jambuluwuk Hotel \& Resort Petitenget melalui proses seleksi telah resmi menunjuk PT. Wahyu Di Graha sebagai kontraktor utama pada proyek pembangunan Jambuluwuk Hotel \& Resort Petitenget. Proyek Pembangunan Jambuluwuk Hotel \& Resort Petitenget, merupakan proyek kompleks di kawasan dengan skala aktifitas cukup besar pada area lingkungan pariwisata yang sedang berkembang, dengan ketinggian 18 meter, 7 lantai dari permukaan existing, meliputi area Basement, semi- Basement, dan bangunan berlantai 4 serta area rooftop pool and event party dengan target waktu pelaksanaan 900 (sembilan ratus) hari kerja. Pembangunan hotel ini melibatkan alat-alat berat seperti Excavator, Backhoe, Tower Crane, Crawler Crane, Concrete Mixer Truck. Area pekerjaan hotel ini terletak berhimpitan dengan fasilitas-fasilitas umum dan pribadi seperti restaurant Mirror Garden, villa-villa, dan area perumahan warga setempat.

Tujuan penelitian ini adalah mengetahui jenis risiko dominan (major risk) yang terjadi pada kegiatan proyek pembangunan Jambuluwuk Hotel $\&$ Resort Petitenget.

\section{MANAJEMEN K3}

Manajemen Keselamatan dan Kesehatan Kerja (MK3) adalah bagian keseluruhan dari sebuah sistem manajemen secara utuh yang meliputi struktur organisasi dan sumber daya, dibutuhkan guna terciptanya tempat kerja yang aman, efisien dan produktif dalam rangka pengendalian risiko-risiko yang berkaitan dengan K3 dalam setiap aktivitas kegiatan pekerjaan (Djoko, 2007).

Rencana Keselamatan \& Kesehatan Kerja adalah kunci sebagai acuan kinerja dalam keamanan pekerjaan pada proyek konstruksi yang ingin melindungi para pekerjanya, personel yang ada dilapangan, seperti peraturan umum yang memberikan petunjuk bagaimana mengurangi kecelakaan dan memberikan perlindungan terhadap aset/properti. Perencanaan K3 meliputi :

a. Identifikasi bahaya (hazard identification), penilaian dan pengendalian risiko (risk assessment and risk control) yang dapat diukur

b. Pemenuhan terhadap peraturan, perundangan dan persyaratan lainnya

c. Penentuan tujuan dan sasaran

d. Program kerja secara umum dan program kerja secara khusus

e. Indikator kinerja sebagai dasar penilaian kinerja K3.

\section{Pelaksanaan Teknis Rencana Keselamatan dan Kesehatan Kerja}

Untuk mewujudkan pelaksanaan dari rencana program K3 harus adanya upaya-upaya dalam tindakan pada proses pelaksanaan yang berkelanjutan (Khurnia, 2012). Upaya-upaya berikut dapat seperti :

\section{Alat Pelindung Diri (APD)}

Mempersiapkan peralatan/alat pelindung diri guna mengurangi cidera dan mencegah timbulnya penyakit akibat kerja.

\section{Peralatan K3}

Atas dasar memperhitungkan kekuatan dari metode kerja dan kebutuhan peralatan yang akan digunakan untuk mencegah terjadinya kecelakaan agar dipersiapkan.

3. Peninjauan ulang kontrak

Pemilihan saat menerima atau membeli barang dan jasa, mitra kerja perusahaan harus terjamin dalam artian memenuhi persyaratan K3 agar dipastikan pada saat menggunakan barang dan jasa dapat dijelaskan kepada semua pihak yang akan menggunakan barang dan jasa tersebut mengenai risiko-risiko kecelakaan kerja yang dapat terjadi. 


\section{Komunikasi K3}

Komunikasi lewat dua arah yang efektif dan pelaporan secara rutin merupakan sumber penting pelaksanaan K3, semua kegiatan ini harus didokumentasikan, prosedur yang ada harus dapat menjamin pemenuhan kebutuhan tersebut seperti hasil pelaksanaan $\mathrm{K} 3$.

5. Training \& Pelatihan

Organisasi harus menyediakan Sumber Daya Manusia (SDM), sarana dan dana yang memadai untuk menjamin pelaksanaan K3 sesuai dengan persyaratan sistem K3 yang ditetapkan. Dalam memenuhi ketentuan tersebut, organisasi harus membuat prosedur.

6. Inspeksi dan Perbaikan K3

Personel yang terlibat mempunyai kompetensi cukup pengalaman, catatan, rekaman hasil inspeksi, pengujian, dan pemantauan dipelihara dan tersedia dengan baik bagi tenaga kerja, kontraktor yang terkait dan manajemen.

\section{Prosedur Pemeriksaan}

Pemeriksaan yang bersifat inspeksi dapat dilaksanakan secara harian (daily), mingguan (weekly), bulanan (monthly), yang harus dijalankan secara tetap dan kontinyu untuk mempertahankan hasil yang telah dicapai.

\section{Tindakan Perbaikan}

Tindakan perbaikan lebih ditujukan dan bersifat memperbaiki keadaan situasi terhadap bahaya yang akan timbul. Tindakan perbaikan yang dilaksanakan dilapangan secara umum menjadi tanggung jawab pimpinan unit kerjanya, dan perbaikan dapat dilakukan dengan temuan menyimpang dari ketentuan/strandar yang ditentukan dalam sasaran dan program Kerja K3.

9. Prosedur Pengendalian

Pengendalian disini maksudnya adalah untuk memantau dan mengukur pencapaian kinerja K3, yang meliputi proses $\mathrm{K} 3$ didasarkan dengan adanya kinerja masing-masing proses kegiatan dan sasaran.

\section{Pengendalian Administratif}

Prosedur dan instruksi kerja yang dibuat harus mempertimbangkan segala aspek K3 pada setiap tahapan, rancangan tinjauan ulang prosedur dan instruksi kerja harus dibuat oleh personel yang mempunyai kompetensi kerja dengan melibatkan pelaksana yang terkait.

11. Siklus Penanganan K3

a. Siklus Harian K3

Siklus Harian K3 (Daily Safety Work Cycle) adalah suatu siklus aktifitas safety yang rnempuyai periode ulang setiap hari. Aktifitas ini dilakukan oleh kelompok-kelompok kecil pekerja yang menangani pekerjaan sejenis, dipimpin langsung oleh kepala grup kerja.

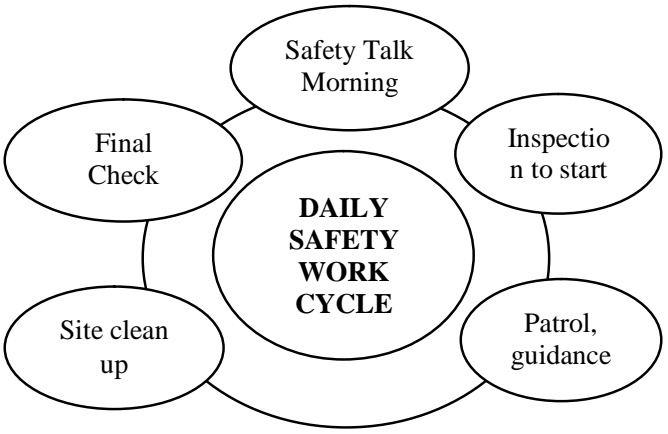

Gambar 1. Siklus aktifitas harian K3

\section{b. Siklus Mingguan K3}

Siklus Mingguan K3 (Weekly safety work cycle) dilakukan periodik mingguan, biasanya pada akhir minggu. Hal ini perlu dilakukan untuk tujuan mengevaluasi oleh manajemen proyek terhadap grup-grup kerja, menyampaikan informasiinformasi dari manajemen proyek kepada grupgrup kerja, serta mengadakan interaksi satu grup kerja dengan grup kerja lainnya, sehingga akan terjadi tukar menukar pengalaman yang diperoleh suatu grup kerja selama satu minggu berjalan.

c. Siklus Bulanan K3

Siklus Bulanan K3 (Monthly safety work cycle) dilakukan secara periodik bulanan, biasanya terletak pada akhir bulan. Hal ini perlu dilakukan untuk tujuan menyampaikan informasi dari manajemen proyek kepada personil, mengevaluasi K3 oleh manajemen proyek terhadap pelaksanaan K3 pada proyek konstruksi selama satu bulan, serta penentuan program-program kerja yang bersifat strategis.

\section{Audit K3}

Organisasi harus menyusun dan memelihara prosedur audit dan program audit dalam rangka pemeriksaan pada sistem manajemen K3, dengan tujuan mengetahui kesesuaian dengan sistim manajemen K3. Program audit lengkap dengan jadwalnya yang dilaksanakan secara berkala, harus didasarkan pada hasil dari penilaian risiko dari aktifitas organisasi dari hasil audit sebelumnya.

13. Investigasi Kecelakaan

Hal ini penting bahwa setiap kecelakaan harus di lakukan investigasi, seperti penyebabnya, dan membuat laporan secara lengkap apa yang terjadi dan mengapa bisa terjadi.

\section{Fasilitas Kesehatan dan Testing Perobatan}

Diperlukan pengaturan terhadap Rumah Sakit terdekat dan Dokter untuk membantu bila terjadi kecelakaan setelah dilakukan pertolongan pertama pada kecelakaan (P3K) di lapangan, seperti halnya menetapkan dan menyiapkan peralatan P3K sendiri. 


\section{Analisis Bahaya}

Menurut Labor Occupational Health Program, bahaya ditempat kerja adalah segala sesuatu di tempat kerja yang dapat malukai pekerja, baik secara fisik maupun mental. Bahaya merupakan potensi yang dimiliki oleh bahan/ material, proses atau cara dari pekerja yang dapat menimbulkan kerugian terhadap keselamatan dan kesehatan jiwa seseorang. Bahaya juga merupakan suatu sumber energi yang dapat menyebabkan terjadinya cidera pada pekerja, kerusakan pada peralatan, lingkungan, dan struktur.

Menurut Soehatman (2009), jenis-jenis bahaya Keselamatan dan Kesehatan Kerja (K3) saat berada di tempat kerja sebagai berikut :

6. Bahaya fisik (Physical Hazard) dapat berupa radiasi, temperatur ekstrim, cuaca, pencahayaan, getaran, tekanan udara.

7. Bahan kimia (Chemical Hazard) bahaya berbentuk gas, cair, padat yang mempunyai sifat racun (toxic), iritasi (irritant), sesak napas (asphyxia), mudah terbakar (flammable), meledak (explosive), berkarat (corrosive).

8. Bahaya biologis (Biological hazard) bahaya yang dapat berasal dari mikroorganisme khususnya yang dapat menimbulkan gangguan kesehatan, seperti bakteri, jamur, virus.

9. Bahaya ergonomik merupakan bahaya yang dapat menimbulkan gangguan pada tubuh secara fisik sebagai akibat dari ketidaksesusaian dan cara kerja yang salah

10. Bahaya mekanis (Mechanical Hazard) bahaya yang terdapat pada benda-benda yang bergerak serta dapat menimbulkan dampak luka bahkan kematian seperti terpotong, tertusuk, tersayat, tergores, terjepit.

11. Bahaya kelistrikan (Electrical hazard) merupakan bahaya yang berasal dari arus aliran listrik.

12. Bahaya psikologi (Psychological Hazard Stress) dapat berupa tekanan pekerjaan, kekerasan ditempat kerja, dan jam kerja yang panjang kurang teratur

\section{Manajemen Risiko}

Manajemen risiko adalah sebuah cara yang sistematis dalam memandang sebuah risiko dan menentukan dengan tepat penanganan terhadap risiko tersebut. Ini merupakan sebuah sarana untuk mengidentifikasi sumber dari risiko dan ketidakpastian, serta dapat memperkirakan dampak yang akan ditimbulkan dan mengembangkan respon yang harus dilakukan untuk menanggapi risiko tersebut. Tindakan manajemen risiko diambil oleh para praktisi untuk merespon bermacammacam risiko. Responden melakukan dua macam hal tindakan dalam manajemen risiko yaitu prihal mencegah dan memperbaiki (Ibrahim,2011).
Menurut Australia/New Zealand Standard atau disebut juga AS/NZS 4360 (2004), risiko adalah suatu kesempatan dari kejadian atau peristiwa yang dapat menimbulkan dampak pada sasaran, risiko diukur berdasarkan adanya kemungkinan terjadinya suatu kasus dan konsekuensi yang dapat ditimbulkan.

Pada Manajemen Risiko dalam perspektif K3 (Soehatman,2009), jenis risiko dapat dikategorikan sebagai berikut:

a. Risiko Keselamatan (Safety Risk)

Risiko keselamatan adalah suatu risiko yang mempunyai kemungkinan rendah untuk terjadi tetapi memiliki konsekuensi besar.Risiko ini dapat terjadi sewaktu-waktu, bersifat akut dan fatal. Kerugian-kerugian yang biasanya terjadi dalam risiko keselamatan adalah cedera, kehilangan hari kerja, kerusakan property dan kerugian produksi dan penjualan.

b. Risiko Kesehatan (Health Risk)

Risiko kesehatan adalah suatu risiko yang mempunyai kemungkinan tinggi untuk kterjadi tetapi memiliki konsekuensi yang rendah.Risiko jenis ini dapat terjadi kapan saja secara terusmenerus dan berdampak kronik. Penyakit-penyakit yang terjadi misalnya gangguan pernafasan, gangguan syaraf, gangguan reproduksi dan gangguan metabolic atau sistemik.

c. Risiko Lingkungan (Enviromental Risk)

Risiko ini berhubungan dengan keseimbangan lingkungan. Ciri- ciri risiko lingkungan adalah perubahan yang tidak signifikan, mempunyai masa laten yan panjang, berdampak besar pada populasi atau komunitas, berubahnya fungsi dan kapasitas habitat dan ekosistem serta kerusakan sumber daya alam

d. Risiko Keuangan (Financial Risk)

Risiko keuangan berkaitan dengan masalah ekonomi, contohnya adalah kelangsungan suatu bisnis, asuransi dan inventasi

e. Risiko Umum (Public Risk)

Risiko ini berkaitan dengan kesejahteraan kehidupan orang banyak. Sehingga hal-hal yang tidak diharapkan seperti pencemaran air dan udara dapat dihindari.

\section{Metode Identifikasi Risiko}

Terdapat bermacam metode yang sering digunakan dalam proses mengidentifikasi risiko untuk mengetahui faktor penyebab atau dampak dari risiko itu sendiri. Berikut beberapa contoh metode dalam mengidentifikasi risiko :

\section{a. Preeliminary Hazard Analysis}

Preeliminary Hazard Analysis adalah suatu metode yang dilakukan jika tidak adanya informasi mengenai suatu sistem baru yang akan dipergunakan. Metode ini biasanya dilakukan pada awal sebelum sistem baru mulai diterapkan. 


\section{b. Failure Mode Effect Analysis}

Failure Mode Effect Analysis adalah metode yang dipergunakan dalam menganalisa sistem yang berhubungan dengan engineering dalam menilai efek dari kegagalan komponen suatu sistem serta mengevaluasi efek dari kegagalan tersebut, sehingga efek dari kegagalan system tersebut dapat dikurangi.

c. Check List

Check List merupakan suatu metode yang digunakan untuk mengetahui sebuah kondisi awal dalam mengevaluasi sebuah perangkat, peralatan, fasilitas dan prosedur operasi dengan teknik memberi tanda/ simbol-simbol pada setiap tahap data yang akan dievaluasi.

d. Hazard and operability Study

Hazard and operability Study (HAZOPS) merupakan metode yang sering digunakan pada industri kimia dalam mengidentifikasi bahaya yang kaitannya dalam memproses bahan kimia serta dampak bahan-bahan kimia tersebut pada lingkungan.

e. Fault Tree Analysis (FTA)

Fault Tree Analysis metode yang digunakan dalam memprediksi atau digunakan sebagai alat investigasi setelah terjadi kecelakaan, konsep ini dilakukan dengan mencari keterkaitan secara berantai yang menyebabkan kecelakaan bisa terjadi.

\section{f. Job Safety Analysis}

Job Safety Analysis atau JSA adalah metode yang dilakukan dalam upaya mengidentifikasi bahaya atau risiko-risiko kecelakaan kerja yang dapat terjadi di tempat kerja dari setiap aspek yang mempengaruhi tahapan pekerjaan tersebut. (Wiyasa,2014)

\section{Analisis Risiko}

Analisis risiko merupakan kegiatan menganalisa suatu risiko dengan menentukan besarnya kemungkinan terjadi dan tingkat dari penerimaan akibat suatu risiko. Tujuan adalah untuk membedakan antara risiko kecil, risiko sedang, dengan risiko besar dan menyediakan data untuk membantu evaluasi dan penanganan risiko (AZ/NZS 4360). Faktor yang mempengaruhi dalam analisis risiko adalah :

a. Sumber risiko

Merupakan asal atau timbulnya risiko yang dapat berupa material, yang digunakan dalam proses kerja, peralatan kerja, kondisi area kerja dan perilaku dari pekerja.

b. Probabilitas

Merupakan besaran kemungkinan timbulnya risiko. Ditentukan dengan menganalisis frekuensi bahaya terhadap para pekerja, jumlah dan karakteristik bahaya yang terpapar pada pekerja, jumlah dan karakteristik pekerja yang terkena dampak bahaya, kondisi area kerja, kondisi peralatan kerja, serta efektifitas tindakan pengendalian bahaya yang telah dilakukan sebelumnya. Faktor probabilitas juga berkaitan dengan faktor perilaku pekerja dikarenakan kurangnya pengetahuan dan kesadaran terhadap bahaya dan sumber risiko yang ada dalam proses kerja dan di tempat kerjanya atau stres yang dialami pekerja yang berpengaruh dalam penurunan konsentrasi pekerja.

c. Konsekuensi

Merupakan besaran dampak yang ditimbulkan dari risiko. Ditentukan dengan analisis atau kalkulasi statistik berdasarkan data-data yang terkait atau melakukan estimasi subjektif berdasarkan pengalaman terdahulu.

\section{Analisis Risiko Kualitatif}

Metode kualitatif ini pada umumnya menggunakan tabulasi sifat karakteristik penelitian melalui skala deskriptif seperti; tinggi, sedang, atau rendah. Hasil dari analisis kualitatif berbentuk matriks risiko dengan dua parameter, yaitu peluang dan akibat. Menurut AS/NZS 4360 seperti tabel berikut:

Tabel 2. Level risiko berdasarkan standar AS/NZS4360

\begin{tabular}{clr}
\hline RISIKO & \multicolumn{3}{l}{ Risiko tidak dapat diterima, kegiatan } \\
SANGAT & $\begin{array}{l}\text { tidak boleh dilanjutkan sampai } \\
\text { TINGGI }\end{array}$ & keadaan tertentu/ upaya mereduksi \\
15- 25 & risiko \\
\hline RISIKO & Risiko perlu pertimbangan untuk \\
TINGGI & $\begin{array}{l}\text { direduksi, kegiatan tidak boleh } \\
\text { dilanjutkan, jika dilanjutkan perlu } \\
\text { tindakan segera }\end{array}$ \\
\hline RISIKO & $\begin{array}{l}\text { Perlu tindakan untuk mengurangi } \\
\text { risiko, disesuaikan dengan }\end{array}$ \\
SEDANG & perhitungan biaya pencegahan dan \\
$4-6$ & waktu yang diperlukan \\
\hline RISIKO & Risiko dapat diterima, pengendalian \\
RENDAH & tambahan tidak diperlukan \\
$1-3$ & \\
\hline
\end{tabular}

Tingkat risiko (level of risk) pada analisis semikuantitatif merupakan hasil perkalian dari variabel konsekuensi, paparan, dan kemungkinan dari risiko-risiko keselamatan kerja yang terdapat pada setiap tahapan pekerjaan.

Nilai risiko $=$ Likelihood $(\mathrm{L}) \times$ Consequences $(\mathrm{C})$

Tingkat atau peringkat dari risiko merupakan alat yang sangat penting pada manajemen dalam pengambilan keputusan, karena melalui peringkat risiko pihak manajemen dapat menentukan prioritas dan penanganan saat mengalokasikan sumber daya pada tahap pekerjaan konstruksi berlangsung. Pada evaluasi risiko akan diperoleh gambaran-gambaran informasi tentang risiko yang ada dalam parameter biaya maupun parameter lainnya. As Low As Reasonably Practicable (ALARP) merupakan salah satu konsep praktis dalam mengevaluasi prioritas 
dari risiko tersebut menimbang terhadap terjadinya risiko, dana, dan waktu untuk mengendalikannya dilapangan. Menggunakan metode dengan konsep ini dapat memungkinkan dan memudahkan kita dalam menetapkan tujuan dan tugas para dutyholders secara non preskriptif (Bhardwaj, 2010).

Menurut AS/NZS 4360 (2004) ada tiga kategori region pada ALARP untuk meninjau peringkat risiko antara lain :

1. Dapat diterima secara luas (broadly acceptable)

2. Dapat ditoleransi (tolerable)

3. Tidak dapat diterima/ tidak dapat ditoleransi (unacceptable)

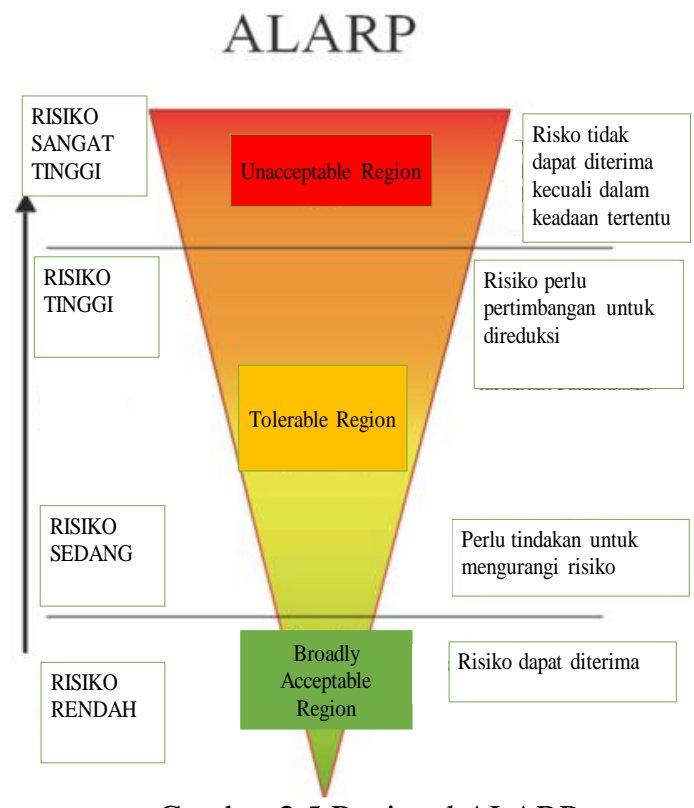

Gambar 2.5 Regional ALARP

\section{METODE}

Penelitian ini menggunakan metode deskriptif kualitatif. Penelitian dilakukan pada Proyek Pembangunan Jambuluwuk Hotel \& Resort Petitenget pada pelaksanaan pekerjaan dari tahap persiapan sampai dengan tahap mekanikal elektrikal.

\section{Jenis dan Sumber Data}

\section{a. Data Primer}

Data primer berupa gambaran identifikasi potensi bahaya melalui JSA (Job Safety Analysis) dan penilaian risiko Keselamatan dan Kesehatan Kerja (K3) yang akan diperoleh melalui survei di lapangan dengan teknik wawancara (interview) dan pengamatan (observation) di area kerja proyek pembangunan Jambuluwuk Hotel \& Resort Petitenget. Kemudian kuesioner dibagikan kepada para responden dan dipandu pada saat pengisiannya, sehingga diperoleh penilaian risiko (risk assesment) terhadap Keselamatan dan
Kesehatan Kerja (K3) yang meliputi frekuensi dan konsekuensi.

b. Data Sekunder

Data sekunder berupa studi literatur, buku, papers, media online dan laporan yang diperoleh dari penelitian-penelitian terdahulu sejenis. Data yang akan ditinjau pada proyek konstruksi seperti : 1) Gambar Kerja, 2) Bill of Quantity 3) Daftar Alat 4) Struktur Unit K3 dikaji untuk mendapatkan identifikasi risiko.

\section{Populasi dan Teknik Sampling}

Populasi dalam metode penelitian ini diartikan sebagai penyebutan sekelompok objek yang akan menjadi sasaran dari penelitian. Populasi penelitian ini merupakan orang-orang yang terlibat langsung pada proyek tempat penelitian.

Penelitian menggunakan teknik purposive sampling adalah pengambilan sampel yang berdasarkan kriteria penilaian pada kemampuan dan pengetahuan responden yang diyakini dapat memberikan jawaban sesuai dengan topik penelitian.

\section{Penentuan Skala Penilaian}

Penilaian dilakukan terhadap tingkat penilaian responden, dengan menggunakan skala likert, akan menunjukan tingkatan dari responden terhadap risiko yang teridentifikasi

\section{Instrumen Penelitian}

Instrumen penelitian digunakan untuk mendapatkan serta mengolah informasi yang diperoleh dari para responden dengan menggunakan pola ukur ketepatan yang sama.

\section{Uji Validitas Konstruk dan Realibilitas Alpha Cronbach}

Uji validitas berguna untuk mengetahui apakah ada pernyataan-pernyataan pada instrumen dalam hal ini kuesioner yang diganti karena dianggap tidak valid dari masing-masing pernyataan dengan skor total Sugiyono (2010).

Uji reliabilitas digunakan untuk mengetahui sejauh mana hasil pengukuran tetap konsisten, apakah responden yang sama akan menghasilkan data yang konsisten atau sama pada waktu yang berbeda. Dengan kata lain, reliabilitas mencirikan tingkat konsistensi. Uji reliabilitas kuesioner dilakukan menggunakan metode Alpha Cronbach, Sampel yang diambil berjumlah sebanyak 20 responden dari total 23 kuisioner yang disebarkan untuk menguji validitas dan relliabilitas dilakukan menggunakan bantuan program aplikasi SPSS 20. Untuk uji validitas $\mathrm{r}$ hitung $>\mathrm{r}$ Tabel maka dinyatakan valid. Nilai $r$ Tabel untuk $N=20$ adalah 0,444 . Jika $r$ hitung $<\mathrm{r}$ Tabel maka dinyatakan tidak valid sedangkan untuk uji reliabilitas diukur dengan skala 0 sampai 1. Nilai Alpha mendekati 1 
menunjukan realibilitas atau alat ukur mendekati akurat Sugiyono (2010).

\section{Kerangka Penelitian}

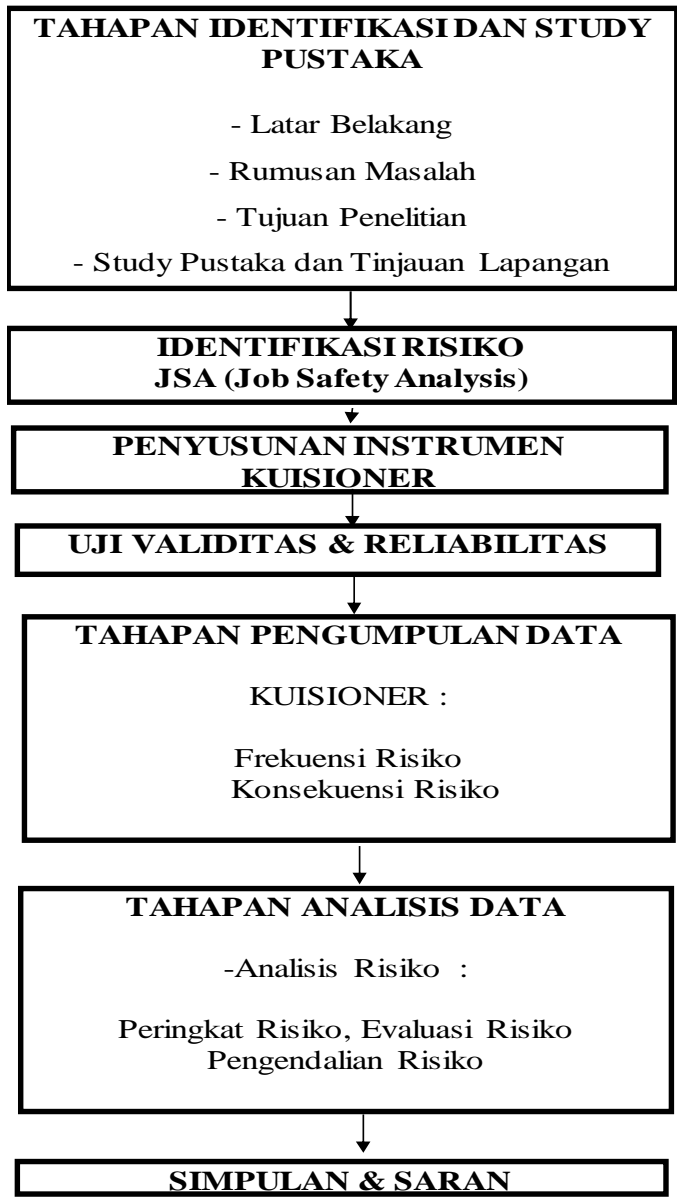

Gambar 3.1 Diagram Alur Penelitian

\section{HASIL DAN PEMBAHASAN \\ Pengumpulan Data}

Data yang diperoleh dari JSA (Job Safety Analysis) ini bertujuan untuk mengidentifikasi risiko dari setiap aktivitas pekerjaan yang dilakukan dari tahapan Pekerjaan Persiapan, Pekerjaan Struktur, dan Pekerjaan Plumbing ME yang berpotensi terhadap timbulnya bahaya dalam pelaksanaannya, dari tahapan tersebut dapat diidentifikasi risiko/ potensi bahaya yang terjadi pada setiap aktivitas yang ada pada masing-masing tahapan. Secara keseluruhan teridentifikasi total sebanyak 275 risiko yang masing-masing terdapat 32 risiko (12\%) dari Pekerjaan Persiapan, 199 risiko $(72 \%)$ dari Pekerjaan Struktur, dan 44 risiko (16\%) dari Pekerjaan Plumbing dan ME.

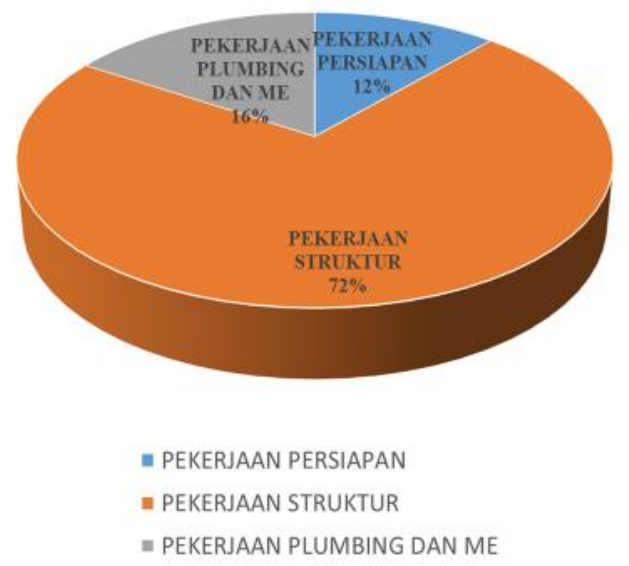

Grafik 4.1 Presentase jumlah risiko pada setiap aktivitas pekerjaan

Teridentifikasi sebanyak 92 risiko (33\%) bersumber pada manusia (people), 57 risiko (21\%) bersumber pada peralatan (equipment), 40 risiko (15\%) bersumber pada bahan (material), dan 86 risiko (31\%) bersumber dari lingkungan (environtment).

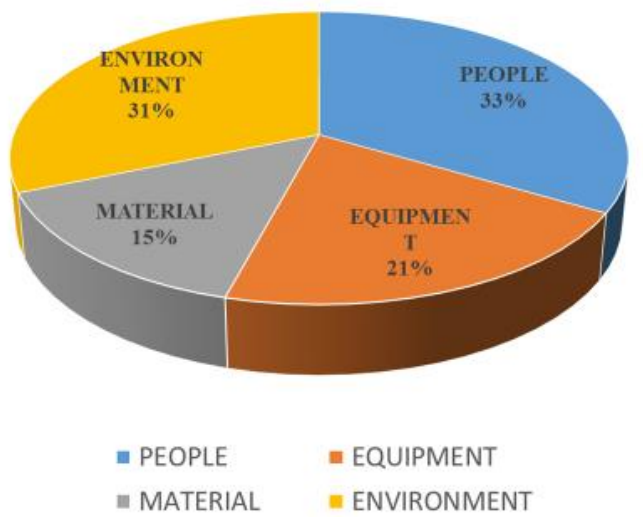

Grafik 4.2 Presentase jumlah risiko berdasarkan sumber risiko

\section{Uji Validitas dan Realibilitas Instrumen Penelitian}

Sampel yang digunakan untuk uji validitas adalah 20 sampel responden dengan taraf signifikan $5 \%$. Terdapat 4 faktor variabel yang dinyatakan tidak valid pada uji validitas dan realibilitas frekuensi, dengan nilai korelasi terkecil 0,121 dan terbesar 0,966 dengan nilai uji realibilitas 0,998. Variabel yang tidak valid akan digantikan sehingga tetap dapat digunakan, sedangkan pada uji validitas dan realibilitas konsekuensi didapat nilai korelasi terkecil 0,608 dan terbesar 0,746 dengan nilai uji realibilitas 0,995 maka dinyatakan valid dan reliabel, dengan nilai Alpha Cronbach $\geq 0,6$ 


\section{Analisis Risiko}

Nilai modus yang diterima melalui kuisioner dapat mewakili representasi terhadap responden. Dari modus jawaban responden terhadap frekuensi (likelihood) dan konsekuensi (consequence) besarnya risiko merupakan hasil kali antara frekuensi dan konsekuensi (risk= likelihood $x$ consequences).

\section{Evaluasi Risiko}

Pengevaluasian peringkat risiko dilakukan melalui ALARP (As Low As Reasonably Practicable). Dengan memasukan nilai besarnya risiko K3 maka dapat ditentukan peringkat risiko K3 dalam pelaksanaan pekerjaan tersebut. Terdapat 143 jenis risiko (48\%) tergolong risiko rendah (low risk), 98 jenis risiko (35\%) tergolong sedang (medium risk), 43 jenis risiko (16\%) tergolong risiko tinggi (high risk), dan 2 jenis risiko (1\%) tergolong risiko sangat tinggi (extreme risk).

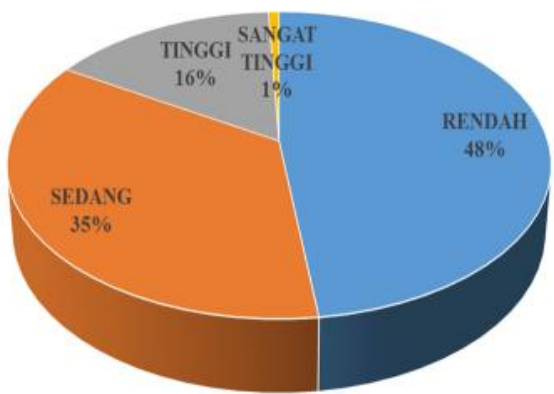

" RENDAH $\|$ SEDANG $=$ TINGGI $\|$ SANGATTINGGI

Grafik 4.3 Presentase peringkat risiko berdasarkan kategori risiko

Terdapat sebanyak 45 macam risiko yang termasuk kategori dominan (major risk) yaitu risiko dengan tingkat kategori tinggi (high risk) dan risiko dengan tingkat kategori sangat tinggi (extreme risk). Faktor lingkungan (environment) cenderung berkontribusi paling besar sebagai penyebab kecelakaan pada pelaksanaan proyek yaitu sebesar $38 \%$, faktor peralatan (equipment) sebesar $31 \%$, manusia (people) sebesar 29\%, dan bahan (material) sebesar $2 \%$.

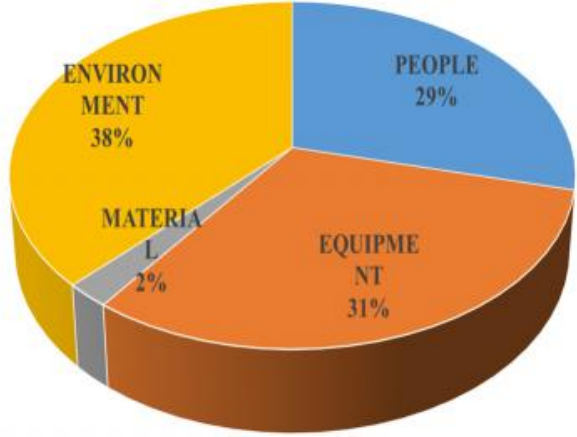

" PEOPLE " EQUIPMENT " MATERIAL "ENVIRONMENT

Grafik 4.4 Presentase risiko dominan berdasarkan sumber risiko

Melalui metode pengendalian risiko berdasarkan sumber risiko yang ada, pekerja diharapkan dapat mengenali potensi bahaya melalui sumbernya sehingga pekerja termotivasi untuk melakukan kegiatan pekerjaan dengan keadaan sehat dan aman.

\section{SIMPULAN DAN SARAN}

Simpulan

Berdasarkan hasil dari penelitian yang telah dilakukan maka, dapat disimpulkan sebagai berikut:

1. Teridentifikasi sebanyak 275 jenis risiko Keselamatan dan Kesehatan Kerja (K3) pada proyek pembangunan Jambuluwuk Hotel \& Resort Petitenget yang teridentifikasi pada 3 tahapan pekerjaan yaitu, tahap pekerjaan persiapan sebanyak 32 jenis risiko (12\%), tahap pekerjaan struktur sebanyak 199 jenis risiko $(72 \%)$, dan tahap pekerjaan plumbing dan ME sebanyak 44 risiko (16\%). Berdasarkan faktor risiko teridentifikasi faktor manusia (people) sebesar 92 risiko (33\%), faktor peralatan (equipment) sebesar 57 risiko (21\%), faktor lingkungan kerja (environment) sebesar 86 risiko $(31 \%)$ dan faktor bahan (material) sebesar 40 risiko (15\%). Terdapat 45 jenis risiko yang tergolong kategori dominan (major risk) antara lain dipengaruhi oleh faktor manusia (people) sebanyak 13 jenis risiko $(29 \%)$, faktor peralatan (equipment) sebanyak 14 risiko (31\%), faktor lingkungan kerja (environment) sebanyak 17 risiko (38\%) dan faktor bahan (material) sebanyak 1 risiko $(2 \%)$.

2. Dari 45 jenis risiko yang tergolong kategori dominan (major risk) diantaranya Terkena manuver alat berat dan kendaraan, Alat berat terguling karena area galian longsor/ amblas, Tali seling Tower Crane terputus/ terjerat pada saat pengoperasian, Muatan jatuh dari Tower Crane, Swing Tower Crane melewati batas 
area proyek, cenderung bersumber pada lingkungan kerja (environment) dan peralatan kerja (equipment).

\section{Saran}

Adapun saran yang dapat disampaikan melalui penelitian ini adalah sebagai berikut:

1. Dalam upaya peningkatan rasa aman dalam bekerja pada proyek konstruksi diperlukannya evaluasi yang bersifat rutin untuk selalu mengingatkan pentingnya bekerja dalam keadaan sehat dan aman seperti melakukan siklus aktivitas penanganan K3 secara periodik harian, mingguan, dan evaluasi bulanan dapat dimulai dari kelompokkelompok kecil pekerja yang menangani pekerjaan sejenis, dipimpin langsung oleh kepala grup kerja.

2. Perlunya dilakukan penelitian lebih lanjut untuk mengetahui besarnya biaya yang dikeluarkan dan keuntungan yang diperoleh dari pengendalian risiko dominan.

\section{DAFTAR PUSTAKA}

Adityanto, B. \& Irawan, S. 2012. Manajemen Risiko Keselamatan dan Kesehatan Kerja Pada Pekerjaan Struktur Bawah dan Struktur Atas Gedung Bertingkat. Skripsi. Semarang: Universitas Diponegoro

AS/NZS 4360 2004. The Australian And New Zealand Standard on Risk Management. Broadleaf Capital International Pty. NSW Australia

Andhika, S. K. 2013. Perbandingan Tingkat Kinerja Keselamatan dan Kesehatan Kerja Sebelum dan Sesudah Penerapan OHSAS 18001 Di PT.PHARPOS, Tbk. Jurnal.Volume 10, Nomor 2, Juli, Tahun 2013, Halaman

99-120. Semarang: Universitas Diponegoro

Bennet, N.B \& Silalahi. 1995. Manajemen Keselamatan dan Kesehatan Kerja. PT. Binaan PustakaPresindo. Jakarta

Bhardwaj, J. R. 2010. Industrial Disaster Risk Management Training Modules. Bhopal Available from: http://www.hrdp-idrm.in

Bird, F.E. and Germain, George L. 1985. Practical Loss Control Leadership, Institute publishing, Loganville, GA. U.S.A.

Colling, A.D. 1990. Industrial Safety Management and Technology. Prentice Hall.

Djoko.S. 2007. Sistem Manajemen Keselamatan dan Kesehatan Kerja Proyek (Project Safety \& Health Management). Departemen Pekerjaan Umum. Jakarta.

Depnakertrans Jatim. 2014. Tinjauan Filsafat dan Perspektif K3 Era Kekinian. Avaible from URL: http://disnakertransduk.jatimprov.go.id/disnak erlama/index.php?option=com_content\&view $=$ article\&id=649:tinjauan-filsafat-danperspektif-k3-era-kekinian

Flanagan, R.N. 1993. Risk Management and Construction. Blackwell Science. London

Godfrey, P. 1996. A Guide to Systematic Management of Risk from Construction. CIRIA. London.

Heinrich, H.W. 1931. Industrial Accident Prevention, A Scientific Approach. McGrawHill Book Company Inc. New York

Ibrahim, J. K. 2011. Pelaksanaan Program Keselamatan Dan Kesehatan KerjaKaryawan PT. BITRATEX INDUSTRIES. Skripsi.Semarang: Universitas Diponegoro.

Juliansyah. N. 2011. Metodologi Penelitian. Kencana Prenada Media. Jakarta

Khurnia, K. A. P. 2012. "Identifikasi dan Analisis Risiko Keselamatan dan Kesehatan Kerja Pada Area Produksi di PT. SIERAD PRODUCE,Tbk". Skripsi. Departemen Keselamatan dan Kesehatan Kerja Fakultas Kesehatan Masyarakat. Depok: Universitas Indonesia

Puspita, I. 2012. Statistik Deskriptif. (makalah online) April 11. Avaible from : http://www.scribd.com/doc/88868567/STATI STIK-DESKRIPTIF\#scribd

Runtu, D. 2016. “K3 Jangan Jadi Beban”. Tokoh, 11 - 17 Januari, Edisi 883 hal: 23

Soehatman, R. 2009. Sistem Manajemen Keselamatan dan Kesehatan Kerja. OHSAS 18001. Dian Rakyat, Jakarta.

Sucita, I. K. \& Broto, A. B. 2011. Identifikasi dan Penanganan Risiko K3 Pada Proyek

Konstruksi Gedung. Jurnal.VOL.10, NO. 1,Januari 2011. Jakarta.

Sugiyono. 2010. Metode Penelitian Kuantitatif Kualitatif. R\&D Alfabeta. Bandung

Winjani, D. 2010. “Analisis Kualitatif Hubungan Antara Hasil Analisis Risiko Keselamatan Kerja dengan Kejadian Kecelakaan Kerja yang Telah Terjadi pada Pekerja di Unit Shredder Facility PT HOLCIM INDONESIA Tbk". Skripsi. Program Studi Kesehatan Masyarakat Fakultas Kedokteran dan Ilmu Kesehatan. Jakarta:Universitas Islam Negeri Syarif Hidyattulah.

Wiyasa, W. 2014. Manajemen Risiko Keselamatan Dan Kesehatan Kerja (K3) Pada Proyek Pembangunan Ciputra World Jakarta. Tesis. Program Magister Teknik Sipil Universitas Udayana Denpasar. 